\title{
Numerical and Experimental Investigations on the Defect Tolerance of Brazed Steel Joints
}

\author{
Adrian Lis, Michael Koster and \\ Christian Leinenbach, Duebendorf, \\ Switzerland
}

Based on the combination of FE-calculations and experimental results a defect assessment procedure for brazed steel joints was developed in the present work, which reliably takes into account the effect of different steel heat treatments and defined artificial defects in the braze layer. Tensile tests with defect free joints consisting of X3CrNiMo13-4 as substrate material and of $\mathrm{Au}-18 \mathrm{wt} . \mathrm{\%} \mathrm{Ni}$ as filler metal serve as a basis to simulate the elastic-plastic material behaviour. By correlating experimental and numerical methods, failure criteria could be derived which indicate and predict failure of brazed components. These failure criteria were also presumed to calculate the maximum tolerable loads for specimens containing different defects. The results show that the simulations correlate very well with the experimental results. Furthermore, they provide a possibility to analyze the failure behaviour for different defect types and the influence of different heat treatments on the joint strength.
Brazing is a method of consistent joining for a wide range of materials. Due to its advantages such as fast processing times and the low manufacturing costs, brazed compounds are applied in many industrial fields, e.g., for the production of power electronic compounds or in automotive engineering. Especially the relatively low process temperatures compared to welding and the possibility to join different materials, e.g., steel to ceramics, qualify brazing for many seminal applications in aerospace or energy production $[1,2]$. The use of advanced joining techniques, as e. g., high temperature (HT) furnace brazing, is economically efficient and allows the production of highly loaded components such as turbo compressor impellers or turbine parts [3]. HT-brazing is performed at $\mathrm{T}>900^{\circ} \mathrm{C}$ in vacuum or with a shielding gas. Due to their good mechanical properties (HT-) brazed joints are often used in components, which are exposed to complex loading conditions, comprising mechanical, thermal or thermo-mechanical loads.
To guarantee a failure free service life, detailed studies on the behaviour of brazed components under different loading conditions are crucial. However, their mechanical behaviour is different from bulk materials. Brazed joints represent a heterogeneous anisotropic system consisting of base material, filler metal and diffusion zone. The different elastic-plastic properties of base material and filler metal lead to constraining the relatively thin braze layer and the formation of complex triaxial stresses in the brazing zone under mechanical loading. The resulting hydrostatic stresses lead to higher tolerable loads compared to the unconstrained filler metal [4].

Furthermore, brazing defects can lead to a significant decrease of joint strength. Defects such as pores or incomplete gap filling can result from local contaminations or entrapped gas. To estimate the influence of defects on welded structures or bulk materials, defect assessment procedures, such as the R6 method, BS7910 or SINTAP have been developed for quasistatic loading con- ditions $[5,6]$. These defect assessment procedures are based on failure assessment diagrams (FADs) which offer a method to calculate failure limits by considering the structure's resistance to plastic collapse and its resistance to fracture. In the scope of previous investigations, it was shown that they can also be applied for brazed steel joints [7].

Beside the procedures mentioned above, some efforts were made to investigate brazed joints from a detailed mechanical point of view.

Konchanomai et al. [8] combined methods derived from fracture mechanics and finite element (FE) calculations and successfully characterized crack propagation in brazed joints by making use of the stress intensity factor range $\Delta \mathrm{K}$ as well as the Jintegral range $\Delta \mathrm{J}$. This approach lead to the identification of threshold values for $\Delta \mathrm{K}_{\text {th }}$ and $\Delta \mathrm{J}_{\mathrm{th}}$ representing the resistance of the investigated brazed components to fatigue crack growth. Ghovanlou [9] studied the strength of brazed joints considering different mechanical properties of the base 
material and pointed out that a higher yield stress of the substrate gives rise to a higher joint strength using the same filler metal. Additionally, values for fracture toughness were calculated approving that the specimen geometry significantly affects the fracture behaviour.

Bosco et al. [10] introduced how to control toughness as well as strength of a $\mathrm{Cu}^{-}$ Sn system by transforming brittle phases within the braze layer into more ductile phases with appropriate process temperature and heat treatment. Thus mechanical properties of brazed components can be optimized regarding the requirements of tions and experimental results, this work aims at the improvement of a previously developd defect assessment procedure for brazed steel joints $[7,11]$ which takes into account the effect of different heat treatments, i.e., the mechanical properties of base materials, and of defined artificial defects in the braze layer. certain applications.

Based on the combination of FE calcula-

\section{Materials}

Two substrate plates with the dimensions $300 \times 100 \times 25 \mathrm{~mm}$ consisting of the softmartensitic stainless steel X3CrNiMo13-4 (AISI CA 6-NM) were joined by HT-furnace brazing using a special brazing jig. This steel is characterized by good corrosion behaviour and thermal resistance. The high amount of chrome qualifies the substrate for applications where corrosion resistance is needed, e.g., for the production of pumps, compressors or water turbines. The chemical composition of the substrate is shown in Table 1.

The steel plates were joined using foils of the binary alloy $\mathrm{Au}-18 \mathrm{wt} . \mathrm{\%} \mathrm{Ni}$ with a thickness of $100 \mu \mathrm{m}$ as filler metal. The brazing process was performed in an industrial gas furnace (SOLO Profitherm 600) under pure hydrogen as shielding gas. The brazing process was performed at $1020^{\circ} \mathrm{C}$ for 20 min. After cooling down to room temperature, two different heat treatments (HTM) were performed. HTM 1 consists of one

\begin{tabular}{|c|c|c|c|c|c|c|c|}
\hline & $\mathrm{C}$ & $\mathrm{Si}$ & $\mathrm{Mn}$ & $\mathrm{Cr}$ & $\mathrm{Mo}$ & $\mathrm{P}$ & $\mathrm{Ni}$ \\
\hline Min. & - & - & - & 12 & 0.3 & - & 3.5 \\
\hline Max. & 0.05 & 0.7 & 1.5 & 14 & 0.7 & 0.04 & 4.5 \\
\hline
\end{tabular}

Table 1. Chemical composition of X3CrNiMo13-4

a)

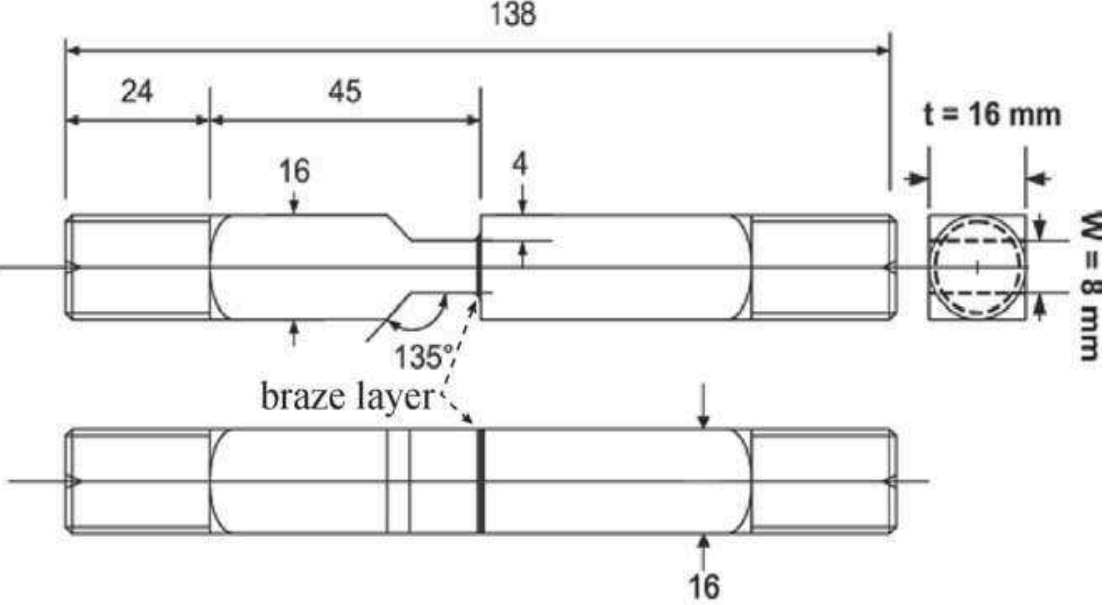

b)
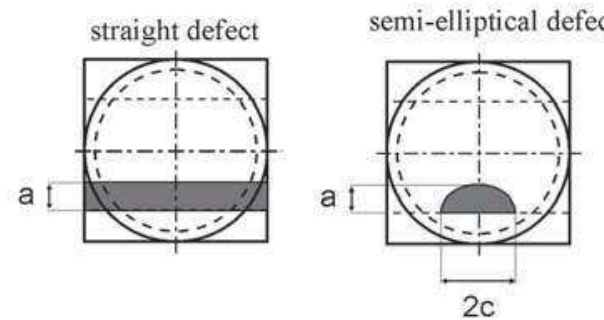

Figure 1. a) T-shaped specimens and b) artificial defects introduced in the braze layer tempering step at $520^{\circ} \mathrm{C}$ for $5.5 \mathrm{~h}$. HTM 2 includes two subsequent tempering steps at higher temperatures. To determine the mechanical properties of the base material in the two different HTMs, tensile tests were performed with standard round specimens $(\varnothing 10 \mathrm{~mm})$. Additionally, T-shaped specimens (Figure 1a) were investigated. In comparison to round specimens, Tshaped geometry is technically more complex but is representative for the geometry of many technical applications where abrupt changes in cross sections nearby braze layers often occur. Beside defect-free T-joints, further specimens containing artificial defects were investigated. Figure $1 \mathrm{~b}$ shows schematically the defects that were introduced in the braze layer by electrical discharge machining (EDM).

Concerning the shape of the defects, straight defects and semi-elliptical defects were investigated. The defect size varies for straight defects from $\mathrm{a}=0.5 \mathrm{~mm}, \mathrm{a}=1 \mathrm{~mm}$, $\mathrm{a}=2 \mathrm{~mm}$ to $\mathrm{a}=4 \mathrm{~mm}$. Semi-elliptical defects were investigated for $\mathrm{a}=0.75 \mathrm{~mm}$, $\mathrm{a}=1.5 \mathrm{~mm}$ to $\mathrm{a}=3 \mathrm{~mm}$ and are characterized by the constant ratio a/c $=2 / 3$ (cf. Figure $1 b)$.

\section{Experimental Results}

The mechanical characterization of the substrate material is an important part regarding an overall understanding of the deformation and failure behaviour of the brazed steel joints. For tensile tests, a servo-hydraulic testing machine was used. The specimens were tested at room temperature with a deformation velocity of $30 \mathrm{~mm} / \mathrm{min}$. Figure 2 shows the averaged stress-strain curves of the steel substrates as measured in 6 individual tests for each HTM. The small deviation of the derived values listed in Table 2 shows the good reproducibility of the measured material responses.

The stress-strain curves for the substrate material in different HTMs show that the different HTMs lead to a significant difference in the mechanical properties. However, higher values for e. g., yield strength $\sigma_{\mathrm{y}}$ and ultimate tensile strength $\sigma_{\text {UTS }}$ for HTM 1 lead to a reduction of ductility expressed by the elongation to fracture, A, compared to HTM 2. Further Vickers-Hardness measurements confirm this analysis. Table 2 shows typical parameters derived from stress strain curves and hardness values for the substrate after HTM 1 and HTM 2. Mechanical parameters for the gold based filler material which are based on previous investigations in [7] are specified in Table 2, too. It 
should be noted that $\sigma_{\text {UTS }}$ of the filler alloys is lower than the corresponding value for HTM 1 but higher than $\sigma_{\text {UTS }}$ of HTM 2.

Similar to the experiments with standard round specimens, tensile tests were performed with T-shaped specimens to observe the influence of the specimen geometry on the joint strength. Beside defectfree T-joints, also defect containing specimens were investigated to study the influence of various defects on the quasistatic nominal strength of the assumed defect free cross section, $\sigma_{\text {nom,max }}$. The results are shown in Table 3 as a function of defect type and size, as well as for the different HTMs.

Generally, defect free T-shaped specimens provide higher nominal tensile strengths after HTM 1 compared to specimens after HTM 2. However, it can be observed that for increasing defect sizes, the ratio $\sigma_{\text {nom,max }}(\mathrm{HTM} 2) / \sigma_{\text {nom,max }}($ HTM1) increases. For a certain defect size $\sigma_{\text {nom,max }}($ HTM2) even exceeds $\sigma_{\text {nom,max }}(\mathrm{HTM} 1)$. In the case of semi-elliptical defects this occurs when the defect size reaches a value of a $=3 \mathrm{~mm}$. Brazed T-joined specimens after HTM 1 containing straight defects with $\mathrm{a}=1 \mathrm{~mm}$ already fail at a lower load compared to HTM 2. In general, increasing defect sizes lead to a decrease of $\sigma_{\text {nom,max }}$ for both HTMs, but this decrease is less pronounced for HTM 2 than for HTM 1.

Fracture always occurred in the braze layer except for some of the defect free specimens after HTM 2 where the substrate failed. Additional Scanning Electron Microscope (SEM) investigations show that the fracture surface is mostly characterized by plastic deformation features (Figure 3).

Beside this characteristic fracture pattern, which amounts $>95 \%$ of the fracture surface, a region close to defect is generally characterized by a smooth fracture surface. Detailed investigations show that this region, which is located in the vicinity to the former steel-filler alloy interface in the brazing zone, most likely represents the area of the crack origin.

\section{Modeling and Analysis with Finite Elements}

The tensile tests with T-joint specimens were additionally simulated by FE methods. The aim was to determine the critical limit loads, numerically. A 3D model of the joint geometries was created with the FE software Abaqus 6.10-EF. Ideal bonding between the steel and the filler metal was assumed. A mesh of hexahedral brick ele- ments with 8 nodes (C3D8R) was created. In the brazing zone the element size was reduced to $0.05 \mathrm{~mm}$, whereas the element size in the base material was set to $0.25 \mathrm{~mm}$. The mesh size was chosen as an optimum between the accuracy of the sim-

Figure 2. Stress strain curves for substrate material in different HTMS

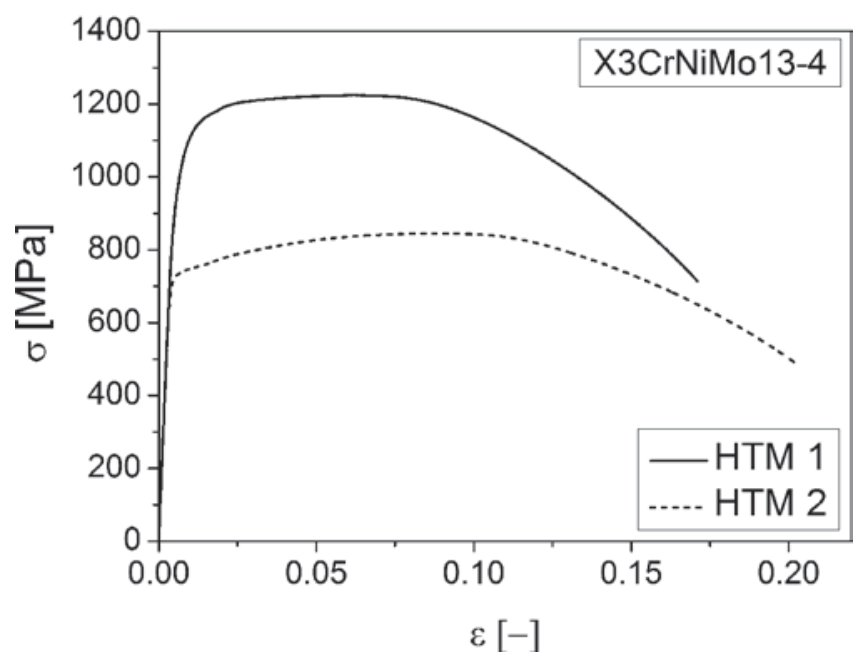

\begin{tabular}{|c|c|c|c|c|c|}
\hline & E $[\mathrm{GPa}]$ & $\sigma_{y}[\mathrm{MPa}]$ & $\sigma_{\text {UTS }}[\mathrm{MPa}]$ & $\mathrm{A}[\%]$ & $\mathrm{HV} 10$ \\
\hline HTM 1 & $204 \pm 4$ & $1017 \pm 2$ & $1224 \pm 2$ & $16.7 \pm 0.1$ & $356 \pm 6$ \\
\hline HTM 2 & $203 \pm 2$ & $726 \pm 3$ & $844 \pm 1$ & $20.0 \pm 0.1$ & $261 \pm 3$ \\
\hline Au-18wt.-\%Ni & 110 & 550 & 925 & 7.3 & $180 \pm 9$ \\
\hline
\end{tabular}

Table 2. Mechanical properties for X3CrNiMo13-4 after HTM 1 and HTM 2 and for Au-18 wt.\%Ni

Figure 3. Fracture surface near the wireeroded defect of a brazed T-joint

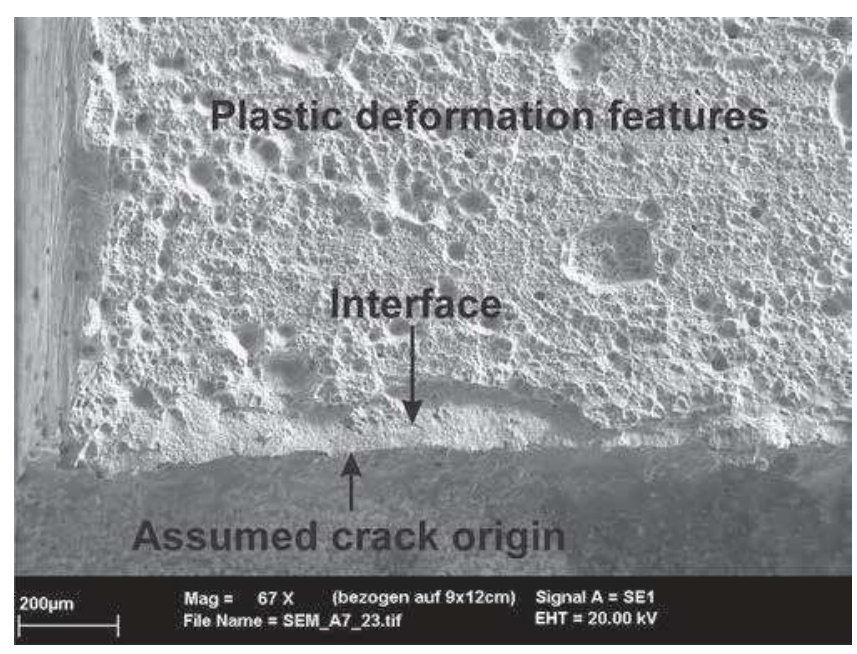

Table 3. Experimental results of tensile tests for brazed T-shaped specimens

\begin{tabular}{|c|c|c|c|}
\hline defect type & defect size a [mm] & $\begin{array}{c}\sigma_{\text {nom,max }}[\text { MPa }] \\
\text { (HTM 1) }\end{array}$ & $\begin{array}{c}\sigma_{\text {nom,max }}[\mathrm{MPa}] \\
\text { (HTM 2) }\end{array}$ \\
\hline defect free & 0 & 1120 & 847 \\
\hline \multirow{3}{*}{ semielliptical } & 0.75 & - & 846 \\
\cline { 2 - 4 } & 1.5 & 944 & 824 \\
\cline { 2 - 4 } & 3 & 648 & 677 \\
\hline \multirow{3}{*}{ straight } & 0.5 & - & 820 \\
\cline { 2 - 4 } & 1 & 594 & 731 \\
\cline { 2 - 4 } & 2 & 453 & 614 \\
\cline { 2 - 4 } & 4 & - & 414 \\
\hline
\end{tabular}


ulated load displacement result and the FE solution time. The deformation behaviour was described by an elastic-plastic deformation law based on Ramberg-Osgood according to equation (1) which was implemented in the FE software.

$\varepsilon=\frac{\sigma}{\mathrm{E}}+\alpha \cdot \frac{\sigma}{\mathrm{E}} \cdot\left(\frac{\sigma}{\sigma_{\mathrm{y}}}\right)^{\mathrm{n}-1}$

The materials' parameters were derived from the stress-strain curves and determined as described in [7] and from Table 2. The elastic-plastic material behaviour is entirely defined by Young's modulus E, yield offset $\alpha$, yield stress $\sigma_{\mathrm{y}}$ and hardening exponent $\mathrm{n}$. The structure as shown in Figure 4 was loaded on the upper surface with a homogeneous tensile stress distribution, whereas the bottom surface was fixed by the boundary condition $\mathrm{u}_{\mathrm{z}}=0$.

The output data was first analyzed considering the resulting strain distribution when the experimentally determined maximum load was applied.
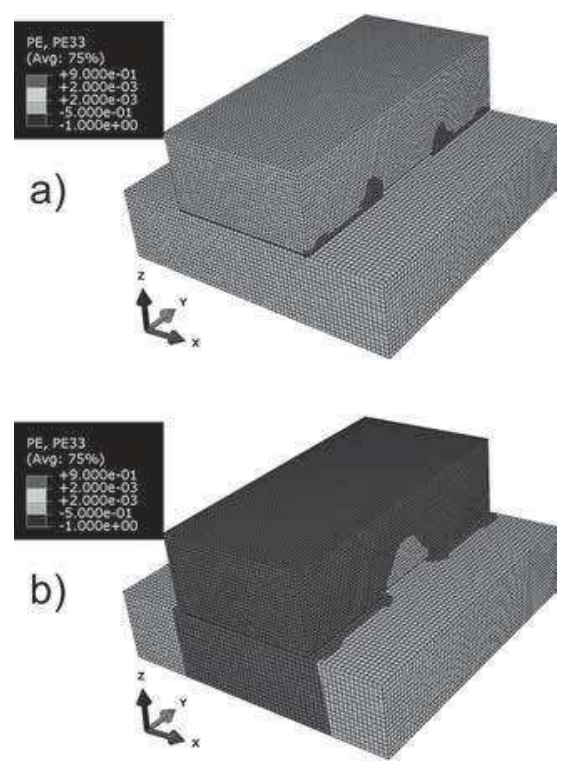

Figure 4. Distribution of elastic- plastic strains for T-joints with semielliptical defects $(a=1.5 \mathrm{~mm}$ ) after a) HTM 1 and b) HTM 2

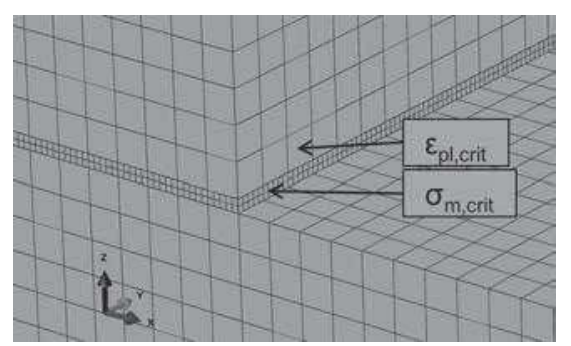

Figure 5. Schematic identification of failure criteria of the interface elements
The results of the performed simulations confirm that the heat treatment strongly influences the strain distribution over the structure. The bright areas in Figure 4 represent elastic material behaviour, whereas the dark areas forecast plastic strains exceeding the $0.2 \%$ - yield limit. Defect containing loaded joints, e.g., with semi-elliptical defects, give a different elastic-plastic response for HTM 1 (Figure 4a) and HTM 2 (Figure 4b). While for HTM 1 plastic strains are restricted to a small local volume around the defect and to the filler alloy, large volume of the substrate after HTM 2 plastifies when applying the experimentally determined limit load. These results can also explain the higher values of $\sigma_{\text {nom,max }}$, for HTM 2 for larger defects (Table 3). The increase of the ductility caused by the heat treatment in comparison with the relatively high strength of the filler alloy leads to a decrease of local stresses and strain peaks as well as to a more homogeneous plastic strain distribution over the cross section. Consequently, HTM 2 provides a better defect tolerance of brazed joints compared to HTM 1.

A quantitative defect assessment requires failure criteria which were determined separately for each HTM. Therefore, the experimentally determined nominal tensile strengths of the brazed T-joints (see Table 3) served as critical values for specimen failure in the FE-simulations. Defect free joints were modeled implementing the elastic-plastic material behaviour for each HTM and applying the critical external load. Two different failure criteria were derived from the FE simulations of defect free specimens. One was based on the plastic strain in loading direction of the base material in the vicinity of the interface, while the other one was based on the critical von Mises stress in the braze layer (Figure 5). The analysis of the simulation showed that failure occurred when the plastic strain reached a value of 0.015 for HTM 1 and 0.07 for HTM 2, respectively. These critical amplitudes were determined from substrate elements at the interface.

The reasons for varying critical plastic strain values as a function of heat treatment can be seen in the different elasticplastic properties of the substrate material. For specimens after HTM 1, the ultimate tensile strength of the joint $\left(\sigma_{\mathrm{UTS}}=1224 \mathrm{MPa}\right)$ significantly exceeds the ultimate tensile strength of the filler alloy $\left(\sigma_{\text {UTS }}=925 \mathrm{MPa}\right)$. This effect is caused by constraining effects in the filler alloy that lead to a triaxial stress field including large hydrostatic stresses [4]. As long as the deformation of the substrate material is mainly elastic, the triaxial stress state leads to an increase of the joint strength, but the triaxial stress state is strongly influenced by plastic deformations. The stress-strain curve for HTM 1 shows that plastic deformation of the substrate material increases significantly with slightly increasing loads when the plastic strain exceeds 0.015. At this state, the braze layer is no longer constrained by the steel substrate and the joints fails since the tensile strength of the filler alloy is exceeded.

Another failure mechanism seems to appear for brazed joints after HTM 2. Due to the changed heat treatment pronounced plastic deformation of the substrate occurs at stresses below the ultimate tensile strength of the gold-based filler metal. The base material and the filler alloy both deform plastically. At a plastic strain of 0.07 , the fracture elongation of the filler material is reached. The steel delaminates from the filler alloy leading to specimen failure.

Additionally, the method mentioned above to determine critical plastic strains was applied to deduce values for critical von Mises stresses serving as a further failure criterion. The analysis was focused on the filler material (see Figure 5) where a critical value of $900 \mathrm{MPa}$ was identified for HTM 1, which corresponds to the ultimate tensile strength of the filler metal [7]. This value is considered to be independent from the HTM, therefore it was also transferred to HTM 2. This approach aims to include hydrostatic stress states appearing in the braze layer while loading.

In a series of FE-calculations the failure criteria, which were derived from defect free T-joint specimens, were transferred to the defect containing specimens. The maximum nominal loads on the initially defect free cross sections were determined as a function of the defect geometry and size as shown in Figure 6 and Figure 7. Critical loads as predicted from FE simulations by using the failure criteria were compared to the experimental data from Table 3. While Figure 6a shows a good correlation between the experimentally and numerically determined strengths for all straight defects and both HTMs by applying critical plastic strains in the vicinity of the interface as failure criteria, the defect assessment based on a critical von Mises stress could not cover the failure behaviour of this defect type (see Figure 6b). Using the critical von Mises stress as failure criterion leads to a too optimistic prediction for HTM 
1 and a rather conservative failure curve for HTM 2. In Figure 7a strengths of brazed T-joints with semi-elliptical defects after HTM 1 und HTM 2 are approximated very accurately to the experimental values by applying critical plastic strains. While FE simulations provide a good estimation for the tensile strengths of brazed T-joints after HTM 2 with semi-elliptical defects when using critical von Mises stress, the strength values for HTM 1 are evaluated too conservative (Figure 7b). Consequently, using critical von Mises stress in the filler material as failure criterion appears to be not suitable for an overall defect assessment of brazed joints. Referring this conclusion to real brazed joints means that fracture is not assumed to initiate in the filler metal itself, especially not for HTM 2, but most likely in the vicinity of the interface between substrate material and filler metal.

Compared to the previously published results and to the limit loads predicted by the R6-method [7, 11], the limit loads predicted on the basis of the critical plastic strains are more accurate.

Based on the achieved results further simulations were performed to study the influence of defects that are very difficult to be considered experimentally, like internal defects with varying size, as shown in
Figure 8. Critical values for the plastic strain in the substrate elements at the interface were used as failure criteria. This defect type is of practical interest since it often occurs in brazed components as a result of local surface contamination or entrapped gas. Such defects can be easily detected using ultrasound inspections.

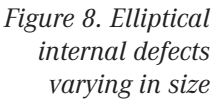
internal defects varying in size a)
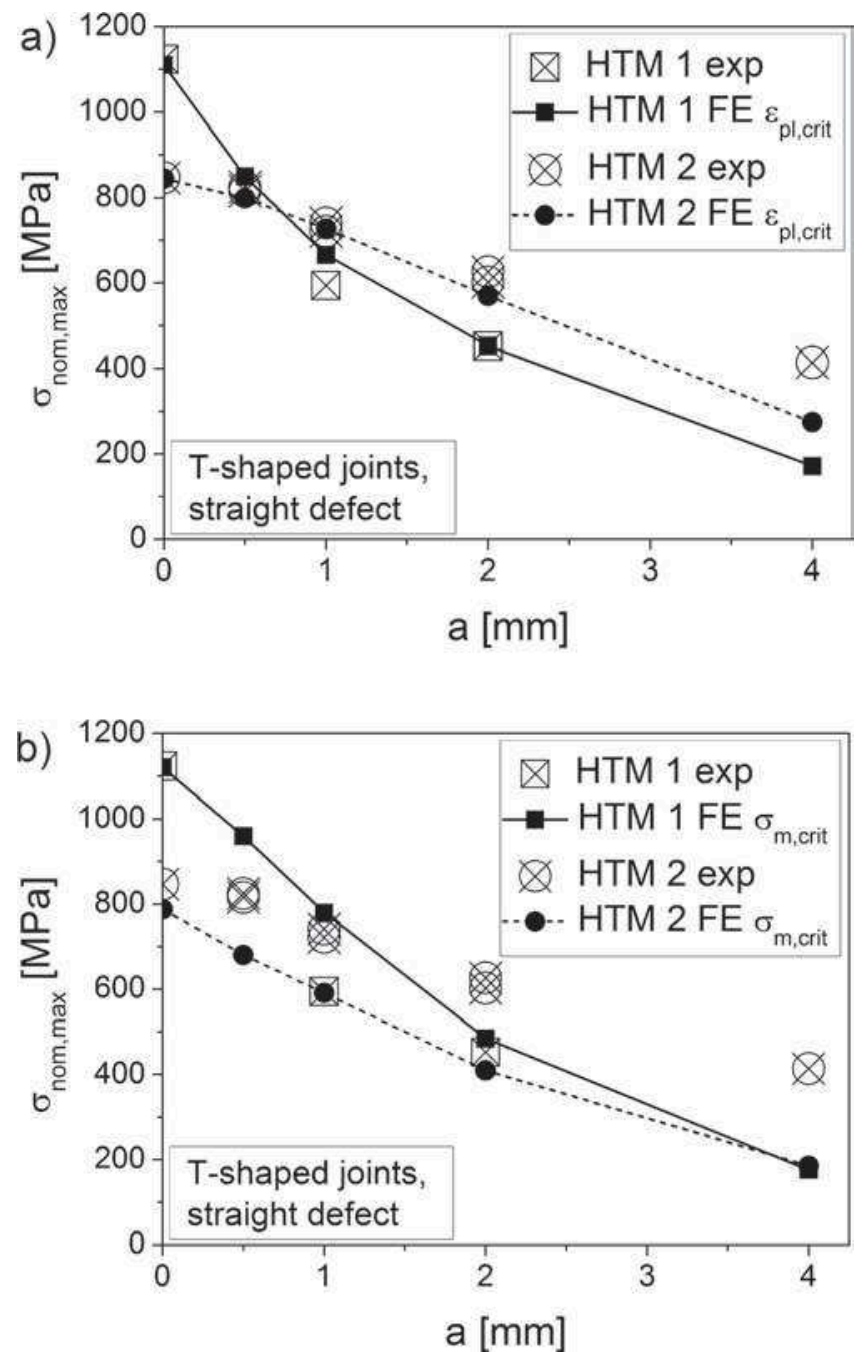

Figure 6. Defect assessment for brazed T-joints with straight defects using a) critical plastic strain, b) critical von Mises stress as failure criteria
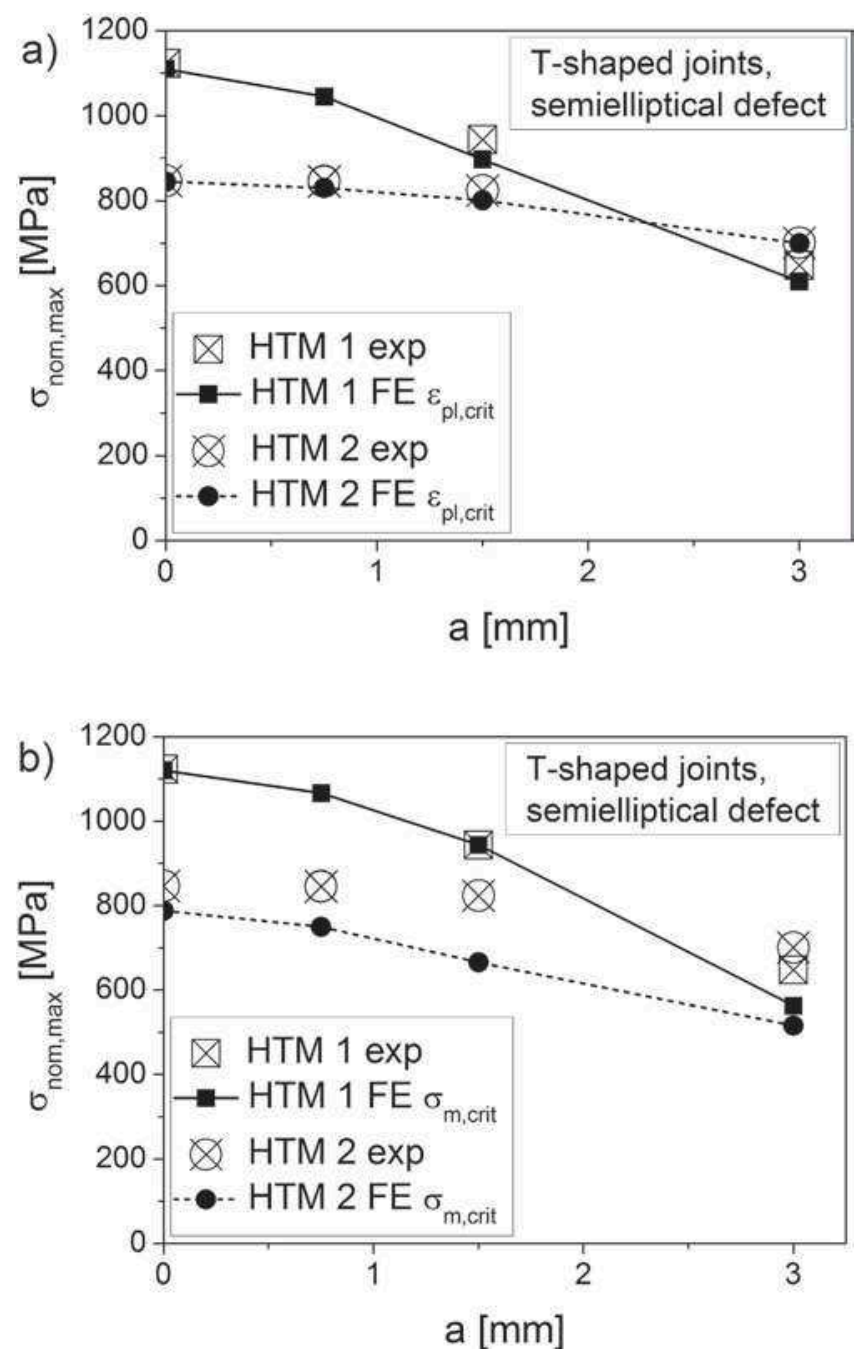

Figure 7. Defect assessment for brazed T-joints with semielliptical defects using a) critical plastic strain, b) critical von Mises stress as failure criteria 


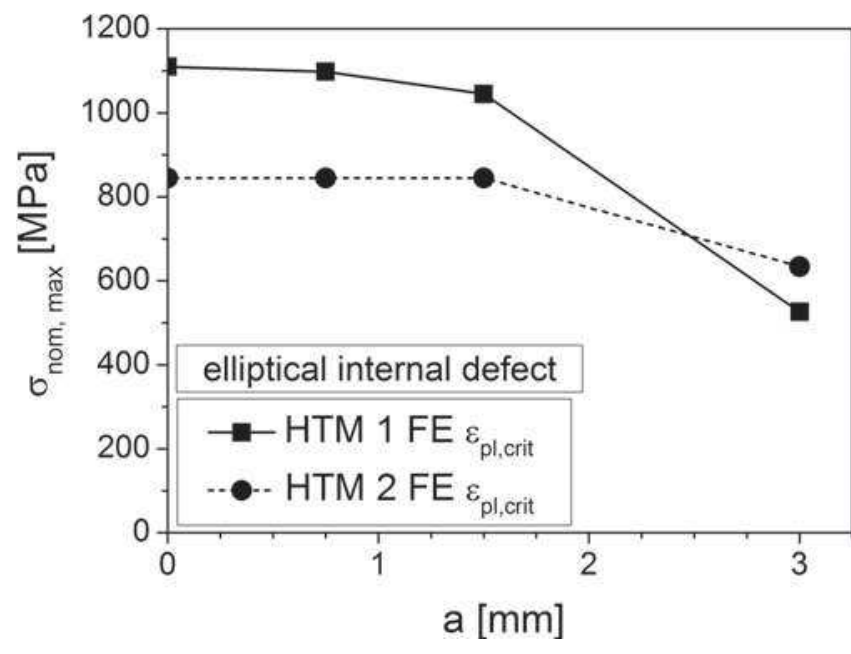

Figure 9. Defect assessment for internal elliptical defects

For the following simulations a hypothetic elliptical defect was positioned in the center of the brazing zone. The size of the defect was varied between $\mathrm{a}=0.75 \mathrm{~mm}$ up to $3 \mathrm{~mm}$ (Figure 8). The results of the simulations show that small defects up to $\mathrm{a}=1.5 \mathrm{~mm}$ do not have a significant influence on the nominal tensile strength of the joint. However, defect sizes of $\mathrm{a}=3 \mathrm{~mm}$ lead to a pronounced decrease of the nominal tensile strength for the given cross section (Figure 9). Furthermore, the simulations show again the influence of the heat treatment on the defect tolerance, which is in correlation with the above mentioned results. As shown in Figure 6 the curves for each HTM intersect, therefore joints after HTM 1 including internal defects offer advan- tages of strength for small defect sizes but fail with a lower limit load when the defect size rises. HTM 2 offers higher strengths for larger defects.

\section{Summary and Conclusions}

This work evaluates the influence of defects on the quasi-static properties of brazed steel joints. Beside size and shape of the defects, the heat treatment strongly affects the ultimate tensile strength.

Based on a series of tensile tests FE simulations were performed. The tensile tests show quantitatively how the heat treatment in combination with defects influences the tensile strength of HT-brazed joints. Defects generally lead to a decrease of the tensile strength, strongly

\section{Abstract}

Numerische und experimentelle Untersuchungen der Defekttoleranz von Stahllötverbindungen. Im Rahmen der vorliegenden Arbeit wurde basierend auf der Kombination aus FE-Berechnungen und experimentellen Ergebnissen eine Methode der Fehlerbeurteilung für Stahllötverbindungen entwickelt, wobei der Einfluss verschiedener Wärmebehandlungen und definiert künstliche Defekte der Lötschicht berücksichtigt werden. Das elastisch-plastische Materialverhalten wurde mittels Zugfestigkeitsprüfungen von hartgelöteten, defektfreien Verbunden aus Stahl X3CrNiMo13-4 und Lot Au-18wt.-\%Ni untersucht. Durch Korrelation von experimentellen und numerischen Methoden konnten Versagenskriterien von hartgelöteten Verbindungen abgeleitet, sowie auch auf fehlerhafte TStoß-Proben, übertragen werden. Die Untersuchungen zeigen eine sehr gute Übereinstimmung der experimentellen Ergebnisse mit den Simulationsergebnissen. Somit können FE-Simulationen neben der Abschätzung des Einflusses von Lötfehlern auch zur Berücksichtigung verschiedener Wärmebehandlungsverfahren eingesetzt werden.

depending on size and shape of the defect. Furthermore, T-joints react more sensitive on large defects after HTM 1, compared to HTM 2. The experimental results achieved for defect free T-joint specimens were used as a reference value to identify appropriate failure criteria for FE-simulations.

The determination of two separate failure limits for plastic strain can be explained by the different stress- strain response of the substrate due to HTM. After HTM 1, the joint failure is closely related to the beginning of plastic deformation of the substrate at the interface, leading to a sudden change of the triaxial stress state in the brazing zone and to specimen failure since the tensile strength of the filler metals is exceeded. Another plastic limit strain was defined for HTM 2 where pronounced yielding of the substrate occurs below the ultimate tensile strength of the gold-based filler metal is reached. Specimen failure occurs when reaching the fracture elongation of the filler material in the interfacial region. These results underline the importance of a good interfacial bonding between the filler metal and the substrate. Due to the different deformation behaviour for HTM 2, stress and strain peaks around defects can be compensated by plastic deformation which causes a less pronounced decrease of the failure load when defect size increases. The FE calculations are in good agreement with the experimental results and offer an optimized method to estimate the influence of defects on the quasi-static joint strength and to exploit the full potential of brazed joints. Applying critical von Mises stress in the filler material as failure criterion did not lead to satisfying results.

\section{References}

1 R. K. Shiue, S. K. Wu, S. Y. Chen: Infrared brazing of TiAl intermetallic using BAg-8 braze alloy, Acta Materialia 51 (2003), pp. 1991-2004

2 T. Ma, M. Zeng, Y. Ji, H. Zhu, Q. Wang: Investigation of a novel bayonet tube high temperature heat exchanger with inner and outer fins, International Journal of Hydrogen Energy 36 (2011), pp. 3757-3768

3 J. Nowacki, P. Swider: Producibility of brazed high-dimension centrifugal compressor impellers, Journal of Materials Processing Technology 133 (2003), pp. 174-180

4 M. E. Kassner, T. C. Kennedy, K. K. Schrems: The mechanism of ductile fracture in constrained thin silver film, Acta Materialia 46 (1998), pp. 6445-6457

5 G. W. Marshall, R. A. Ainsworth: The fracture behaviour of a welded tubular joint: an ESIS TCI-3 round robin on failure assessment meth- 
ods Part II: R6 analysis, Engineering fracture mechanics 69 (2002), pp. 1111-1118

6 S. Webster, A. Bannister: Structural integrity assessment procedure for Europe - of the SINTAP programme overview, Engineering fracture mechanics 67 (2000), pp. 481-514 7 C. Leinenbach, H.-J. Schindler, T. A. Baser, N. Rüttimann, K. Wegener: Quasistatic fracture behaviour and defect assessment of brazed soft martensitic stainless steel joints, Engineering Failure Analysis 17 (2009), pp. 672-682 8 C. Kanchanomai, W. Limtrakarn, Y. Mutoh: Fatigue crack growth behavior in $\mathrm{Sn}-\mathrm{Pb}$ eutectic solder/copper joint under mode I loading, Mechanics of Materials 37 (2005), pp. 1166-1174

9 M. Ghovanlou: Mechanical reliability characterization of low carbon steel brazed joints with copper filler metal, Materials Science and Engineering A 528 (2011), pp. 6146-6156

10 N. S. Bosco, F. W. Zok: Strength of joints produced by transient liquid phase bonding in the Cu-Sn system, Acta Materialia 53 (2005), pp. 2019-2027

11 C. Leinenbach, H. Lehmann, H. J. Schindler: Mechanisches Verhalten und Fehlerempfindlichkeit von Hartlötverbindungen, Materials Testing 49 (2007), pp. 2-9

\section{The Authors of This Contribution}

Dipl.-Ing. Adrian Lis, born in 1986, studied mechanical engineering at the Technical University of Kaiserslautern, Germany, and at the University of Technology Luleå, Sweden. After finishing his diploma thesis in 2011 at the Swiss Federal Laboratories for Materials Science and Technology, Empa, Switzerland, he started to work there on his PhD thesis.

Dr.-Ing. Michael Koster, born in 1978, studied at the University of Kaiserslautern. In collaboration with the ENI Metz and the German-French University in Saarbrücken he finished his studies with a german-french double diploma in mechanical engineering. During his PhD at the Institute of Materials Science and Engineering at the University of Kaiserslautern from 2005-2010, M. Koster studied the very-high cycle fatigue behaviour of railway wheel steels. Since 2010 he is working at the Swiss Federal Laboratories for Materials Science and Technology (Empa) on the integrity of brazed steel joints.

Dr.-Ing. Christian Leinenbach, born in 1974, studied Physics and Materials Science and Engineering at Saarland University, Saarbrücken, Germany, and at Luleå University of Technology, Sweden. In 2000, he graduated (Dipl.-Ing.) at Saarland University. In the same year, he transferred to the Institute of Materials Science and Engineering at the University of Kaiserslautern, Germany, where completed his dissertation on the cyclic deformation behaviour of surface modified titanium alloys in 2004. In 2005, he moved to the Swiss Federal Laboratories for Materials Science and Technology (Empa), where he is currently Head of the Advanced Joining Technologies Group.

You will find the article and additional material by entering the document number MP110372 on our website at www.materialstesting.de 